\title{
Distortion and Rock Guitar Harmony
}

The Influence of Distortion Level and Structural Complexity on Acoustic Features and Perceived Pleasantness of Guitar Chords

Jan-Peter Herbst

University of Huddersfield

\begin{abstract}
Research on rock harmony accords with common practice in guitar playing in that power chords (fifth interval) with an indeterminate chord quality as well as major chords are preferred to more complex chords when played with a distorted tone. This study explored the interrelated effects of distortion and harmonic structure on acoustic features and perceived pleasantness of electric guitar chords. Extracting psychoacoustic parameters from guitar tones with Music Information Retrieval technology revealed that the level of distortion and the complexity of interval relations affects sensorial pleasantness. A listening test demonstrated power and major chords being perceived as significantly more pleasant than minor and altered dominant chords when being played with an overdriven or distorted guitar tone. This result accords with musical practice within rock genres. Rather clean rock styles such as blues or classic rock use major chords frequently, whereas subgenres with more distorted guitars such as heavy metal largely prefer power chords. Considering individual differences, electric guitar players rated overdriven and distorted chords as significantly more pleasant. Results were ambiguous in terms of gender but indicated that women perceive distorted guitar tones as less pleasant than men. Rock music listeners were more tolerant of sensorial unpleasant sounds.
\end{abstract}

\section{Keywords}

Distortion, chords, harmony, guitar, rock music 


\section{Introduction}

This study explores the interrelated effects of distortion and harmonic structure on acoustic features and perceived pleasantness of electric guitar chords to better understand the prevalence of power and major chords in many subgenres of rock music from a psychoacoustic perspective. Although lower-level psychoacoustic features cannot explain chord choices in rock music per se, understanding the underlying acoustic principles might help explain why harmonically simple chords are commonly preferred to more complex chords when played on the distorted guitar.

\section{Rock music harmony}

Set against the standards of art music, rock's harmonic structures may seem simplistic (Baugh, 1993). As Winkler (1978, pp. 3-4) once claimed, "harmonically speaking, the rock message is ingenuous and unsophisticated. The chordal vocabulary is uncluttered [...] The low-tension sonorities are easily identified and hardly innovative". Yet, some advocates of rock have tried to prove the genre's complexity (Mellers, 1973; Moore, 2001). A few researchers have argued for rock to stand in line with the folk music tradition (Belz, 1972). Others have pointed out that rock should be valued by its own standards with aesthetic criteria different to art music (Baugh, 1993; Meltzer, 1970; Wicke, 1990). As Wicke (1990, p. 3) argues, "Rock music is organised according to principles that are neither those of folk music nor those of bourgeois art music. In trying to measure rock against either of these we fail to recognise its musical individuality and significantly distort the perspective from which we view it". Criteria put forth as more suitable for rock include rhythm, loudness and noise (Gracyk, 1996), technology and sound (Baugh, 1993; Wicke, 1990), and performance (Frith, 1996).

In rock music studies, the genre's harmony has proved a subject of some dispute (Covach \& Boone, 1997; Everett, 2008; Holm-Hudson, 2002). While Everett rejects the idea of a "single monolithic style of rock harmony" (2004), De Clercq and Temperley (2011) provided strong evidence for rock music's contrasting approach to common-practice harmony with a statistical corpus analysis covering 100 songs between 1950 and 1990, which accords with Stephenson's (2002) stylistic analysis of the genre. One challenge De Clercq and Temperley (2011, p. 56) faced in their analysis was uncertainty as to "whether something was a major or minor triad. In many cases only the root and fifth of a chord are heard [i.e. 'power chords' which are open fifths on an electric guitar]". Furthermore, they speculated about the discovered preponderance of fourth relationships possibly deriving from the tuning of the guitar (De Clercq \& Temperley, 2011 , p. 67). These two aspects, the frequency of power chords and the role of guitar tuning, highlight the importance of the electric guitar for rock music's harmony.

\section{Guitar distortion}

The 'power chord' has frequently been identified as one of the most relevant chords in rock (Cope, 2010; De Clercq \& Temperley, 2011; McDonald, 2000) and related subgenres of heavy metal (Berger \& Fales, 2005; Lilja, 2015; Walser, 1993). Moore (2001, pp. 148-149) observed "heavy metal's tendency towards greater use of guitar distortion" and its "use of power chords, normally combined with distortion, which [...] in the last decade has become replaced by indi- 
vidual lines". This finding accords with other authors (Berger \& Fales, 2005; Cope, 2010; Walser, 1993). It seems as if greater levels of guitar distortion relate to simpler harmonic structures played on the instrument.

Although distortion is centrally important to rock music, the electric guitar being the primary accompanying instrument of this genre, relatively little research has focused on distorted guitar chords (Berger \& Fales, 2005; Herbst, 2016; Juchniewicz \& Silverman, 2011; Lilja, 2005, 2015; Virtala, Huotilainen, Lilja, Ojala \& Tervaniemi, 2018). Acoustically, distorting a guitar amplifier leads to compressing the signal, a process that produces harmonic and inharmonic overtones and flattens the dynamic envelope. Consequently, the timbre becomes noisier, rougher and more present in perception (Berger \& Fales, 2005, p. 184). On the one hand, difference tones are created that add notes below the fundamental note, increasing the chord's powerful sensation (Roederer 1973, p. 43; Walser 1993, pp. 43-45). ${ }^{1}$ On the other hand, the added overtones extend the upper spectrum. Since distortion strengthens the higher overtones of a guitar signal, beating partials lead to roughness, which in turn increases auditory dissonance (Pierce, 1996, p. 83). For this reason, research in musicology and music theory has approached the perception of distorted guitar chords by spectral analysis (Herbst, 2016; Lilja, 2005, 2015). Based on Helmholtz (1863), the power chord as a simple fifth interval (3:2 relation) is likely to produce less dissonant partials than more complex interval relations do because many partials of the fundamental notes coincide (Lilja, 2005, pp. 10-11). Even added combination tones, an acoustic phenomenon of notes played on the instrument producing additional frequencies (Roederer, 1973, pp. 43-45), arguably do not diminish the chord's pleasantness considerably, but rather increase its powerful sensation when played with a distorted guitar tone (Herbst, 2016, pp. 189-190; Walser, 1993, pp. 42-44).

Although the power chord contains no interval of a third and therefore has an ambiguous chord quality, some research has observed a latent major character (Juchniewicz \& Silverman, 2011; Lilja, 2015). In an empirical investigation, Juchniewicz and Silverman (2011) found participants to perceive terminal power chords played with a distorted guitar tone as major. This impression is likely to have been caused by the fact that the major third is the fifth overtone in the harmonic series (Juchniewicz \& Silverman, 2011, p. 127; Lilja, 2015). Spectrographic analysis has indicated that the harmonic structures of power and major chords are almost identical due to the combination tones produced by distortion (Herbst, 2016, pp. 186-192; Lilja, 2015). However, a recent neurological study (Virtala et al., 2018) did not support the notion that distorted power chords are treated like major chords in the auditory system. Furthermore, it revealed "that a change in the distortedness of the chord (distorted vs. nondistorted) elicited larger and earlier change-related responses than a change in the harmonic structure (dyad vs. triad)" (Virtala et al., 2018, p. 325), suggesting that participants reacted more strongly to the sound qualities than to the harmonic structure. Although the research on the perception of distorted

${ }^{1}$ In the case of a power chord played on the open A string, not only are the fretted notes A (110 $\mathrm{Hz})$ and $\mathrm{E}(165 \mathrm{~Hz})$ produced, but also the difference frequency of these notes $(165-110 \mathrm{~Hz})$, which is an octave $(55 \mathrm{~Hz})$ below the fretted fundamental note of the chord (Walser 1993, p. 43). 
guitar chords is conflicting, there are strong indications that sound qualities and harmonic structures interact and significantly influence the perception of rhythm guitar playing.

Due to their less complex interval relations and greater closeness to the harmonic series, power and major chords have been argued to be less dissonant than minor chords when being played with a distorted tone (Herbst, 2016; Lilja, 2015). The so-called "Hendrix chord", an altered dominant seventh with augmented ninth, representing a mixture of major and minor, was claimed to be the most dissonant of these four chord types owing to the richness of adjacent and thus beating frequencies (Lilja, 2015). However, it should be considered that because it is used so regularly in rock music, listeners might have become accustomed to the sound of the "Hendrix chord" already. This chord theory based on spectral characteristics conforms with De Clercq and Temperley's (2011) canonical study, which found power chords and major triads to be more common than minor triads in rock harmony.

Research on "noise" and "noisy timbres" is helpful in understanding guitar distortion too. Several studies have indicated that noise components in human vocal expression are linked to high arousal and low valence because the human voice "overdrives" in response to negative stimuli (Arnal, Flinker, Kleinschmidt, Giraud, \& Poeppel, 2015; Johnstone \& Scherer, 1999; Mende, Herzel, \& Wermke, 1990). According to Juslin and Laukka's (2003, p. 803) “superexpressive voices" theory, humans are likely to perceive similar affective connotations when hearing instrumental timbres. This indicates that the perception of distorted guitar sounds might be influenced by negative associations based on human experiences of distorted vocal expression. This assumption is supported by a recent study (Wallmark, Iacoboni, Deblieck \& Kendall, 2018) that found that participants hear higher levels of exertion in distorted guitar tones compared to clean guitar timbres, even though the player requires no increased effort to produce such tones because the tone quality is controlled by the amplification chain. The authors speculated that the noisy qualities may trick the listener into inferring more physical effort in the production of the tone, which raised the question whether this effect was mediated by familiarity with guitar playing techniques (Wallmark et al., 2018, p. 340).

\section{Perceptions of consonance and pleasantness}

Investigating the influence of distortion on the perception of guitar chords requires a consideration of issues surrounding consonance and pleasantness. In their review of major-minor and consonance-dissonance duality, Virtala and Tervaniemi (2017, p. 394) concluded that only a "rough distinction can be made between harmony in a musical context and sensory-consonance vs. dissonance in simultaneous sounds, e.g., in chords". As Terhardt (1984) argued, sensory consonance, or "pleasantness", relates to lower-level psychoacoustic features such as roughness, sharpness, loudness and tonalness (harmonicity). According to McDermott, Lehr and Oxenham (2010), harmonicity, defined as the closeness of the acoustic spectrum to the harmonic series, is important for consonance perception, supporting Terhardt's (1984) and Aures (1985) theory. Thus, there is evidence for structural interval relations influencing the psychoacoustic features of a sound (Sethares, 1998; Tenney, 1988; Terhardt, 1984).

Sound features such as high-frequency energy (Juslin, 2000; Lartillot \& Toiviainen, 2007), spectral centroid (Kendall \& Carterette, 1996; Kendall, 2002), inharmonicity (Lartillot \& Toiviainen, 2007), spectral flatness, zero-crossing rate (Lartillot \& Toiviainen, 2007), and auditory roughness (Sethares, 1998; Vassilakis, 2005) are features of timbral noisiness (Elliott, Hamilton 
\& Theunissen, 2013). Extending this body of research, Wallmark et al. (2018) have recently shown that increasing noise levels of an instrument produced by playing techniques (voice and saxophone) or changes in amplifier settings (electric guitar) caused listeners to hear noisy timbral snapshots as physically effortful; listeners disliked such sounds and associated them with negative emotions such as anger and fear (Wallmark et al., 2018, p. 345). This finding is relevant to the study of distorted guitar sounds because it shows that associative and metaphorical factors such as the impression of exertion affect the perception of an instrument's sound.

Consonance and dissonance do not fall into strictly defined categories (Virtala \& Tervaniemi, 2017, p. 396) and their perception depends on personal and cultural factors. Studying Amazonian societies in Bolivia, McDermott, Schultz, Undurraga and Godoy (2016) discovered that consonant sounds are not universally preferred to dissonant sounds. The perception of chords seems to change with greater familiarity increasing the perceived pleasantness (McLachlan, Marco, Light \& Wilson, 2013), which stresses the influence of developmental change through aging and learning. As Virtala and Tervaniemi (2017, p. 398) note, "Brain maturation, musical enculturation, as well as music training still significantly modulate their [major-minor and consonance-dissonance] sensory and affective processing. In musicians, neural and behavioral categorization of major-minor and consonance-dissonance are more accurate than in nonmusicians". A growing body of research indicates that perception and affective responses are also linked to musical genres and that the "role of dissonance among music genres varies drastically [...]. While major-minor and consonance-dissonance have a stereotypical, pronounced role in Western popular music, they are likely to be processed highly differently by, for example, players and listeners of heavy music, jazz, or early music" (Virtala \& Tervaniemi, 2017, pp. 396-398). This is demonstrated by the divergent understandings and usages of dissonant intervals in different genres (Virtala \& Tervaniemi, 2017, p. 394). The musical context as well as semantic, cultural and synesthetic associations can alter perceptions of stimuli, too (Rossing, Moore \& Wheeler, 2002). For example, Wallmark et al. (2018, p. 342) found that listeners rate metal music samples, characterized by the sound of distorted guitars, lowest in brightness compared with other genres such as hip-hop, despite the harshness introduced by high levels of distortion. This result was explained by possible cultural associations of metal music with darkness. To briefly summarize, it can be concluded that emotional judgments and preferences regarding consonance and pleasantness are affected by genre, culture, musical training, personality, musical preferences, listening context, semantics and sociodemographic factors (Ladinig \& Schellenberg, 2012; Vuoskoski, Thompson, McIlwain \& Eerola, 2012).

\section{Synopsis, aims and research questions}

The literature review has shown a growing trend of research on the perception of guitar distortion. However, a closer look reveals that the results are contradictory, fragmentary and based on experiments with highly artificial materials. Juchniewicz and Silverman (2011) used guitar amplifier simulation notwithstanding the evidence that the sonic quality of this technology deviates from valve amplifiers mainly used in rock music (Herbst, 2016, pp. 134-142). The same is true for Virtala et al.'s (2018) study which employed chords created with a synthesizer rather than a recorded guitar. This choice of instrument removed the characteristic temporal envelope 
(Müller, 2015, pp. 26-30) and the required progressive change in spectrum pivotal for the guitar's timbre (Pierce, 1996, pp. 196-199). Furthermore, since the characteristic attack of a plectrum was not captured, the stimulus resembled a plucked style associated with acoustic guitars (Herbst, 2016, p. 34). This implies that Virtala et al.'s (2018) study explored a distorted synthesizer sound rather than a guitar. Similar to the issues regarding the authenticity of the audio samples, neither of the two studies by Juchniewicz and Silverman (2011) and Virtala et al. (2018) considered the level of distortion, therefore neglecting different ratios of compression and extended spectrum (Berger \& Fales, 2005; Herbst, 2016). This is in line with the generally low number of studies using different timbral conditions of the same instrument as stimuli (Goydke, Altenmüller, Möller \& Münte, 2004; Spreckelmeyer, Altenmüller, Colonius \& Münte, 2013; Wallmark et al., 2018). Moreover, while these two studies on guitar distortion focused on listeners' ratings (Juchniewicz \& Silverman, 2011) and brain activity (Virtala et al., 2018), they limited their discussion of the guitar's acoustic features to theoretical deliberations. Yet little is known about the acoustic effects of applying distortion to guitar sounds (Wallmark et al., 2018), let alone the interaction between distortion levels and harmonic structures, as indicated by theoretical argumentations (Berger \& Fales, 2005; Herbst, 2016; Lilja, 2005, 2015) and canonical analyses on rock harmony (De Clercq \& Temperley, 2011). Lastly, while theoretical studies (Berger \& Fales, 2005; Lilja, 2005, 2015) on guitar distortion have not considered individual differences at all, empirical studies did so at least rudimentarily (Juchniewicz \& Silverman, 2011; Virtala et al., 2018).

This study aims to address some of these gaps by combining an acoustic experiment with a listening test, both based on authentic sounds with electric guitars and valve amplifiers. The overarching research interest is to better understand the strong preference of power and major chords in rock music based on acoustic and perceptual evidence. It aims to understand how different levels of distortion and chord complexities affect the acoustic parameters of sensory pleasantness as defined by previous studies (Aures, 1985; Terhardt, 1984) and how they affect perceptive responses to the stimuli. Furthermore, it aims to explore how the acoustic parameters of sensory pleasantness correspond to listeners' ratings and what role individual differences play.

By its very nature, such an experiment must be reductionistic. While certain contextual variables can be included such as gender, age, musical education, familiarity with the instrument, guitar playing experience and a preference for rock, the stimuli nonetheless are rated artificially without the context of larger musical structures and other instruments, without any (sub-)genre association, a typical listening situation or semantic meanings, and without considering the subtly nuanced guitar tones that exist within the plethora of rock music's subgenres. Furthermore, perceived pleasantness cannot be equated directly with musical preferences; in order to take this into account one would have to consider a much wider set of factors and musical stimuli, which is not possible to realize and control in an experimental setting. Similarly, aesthetics within rock and metal genres vary significantly. For example, listeners of extreme metal arguably find different forms of structural and tonal dissonance appealing, and guitar sounds perceived as "heavy" in the 1970s were generally not considered especially heavy in later decades (Berger \& Fales, 2005), which stresses the relevance of historical context for timbre perception. 
The project has three stages. First, it investigates the influence of different guitar tones (clean, overdrive, distortion) on the acoustic properties of chord structures by extracting five acoustic features with Music Information Retrieval (MIR) technology from four guitar chords: power, major, minor and altered dominant, played on three guitars and with five amplifiers (180 recordings, 900 test values). The parameters roughness, sharpness and loudness accord with Terhardt's (1984) and Aures' (1985) empirically validated model of sensory pleasantness and allow, at a later stage, to analyze how listeners respond to these acoustic features through data triangulation. Second, a listening experiment $(N=171)$ systematically tests the perceived pleasantness of the four chords played with clean, overdriven and distorted guitar tones (36 ratings per participant; 6,156 ratings in total). Third, data from the acoustic and listening experiments are triangulated to examine what acoustic properties of the sound are perceived as particularly unpleasant by different groups of people. This approach was successfully validated by Eysenberg, Knauf and Reuter (2017) who studied the "hardness" of musical genres. The following research questions guided the investigation:

\section{Acoustic experiment (stage 1):}

1) How does distortion affect the acoustic properties of guitar chords? How does distortion affect the parameters of sensory pleasantness?

2) What is the relative influence of distortion level to harmonic complexity regarding the acoustic features of guitar chords?

3) How do distortion level and harmonic complexity interact acoustically?

\section{Listening experiment (stage 2):}

4) How do increasing levels of distortion and harmonic complexity affect listeners' perception of pleasantness of guitar chords?

5) What is the relative influence of distortion level to harmonic complexity in listeners' perceptions? How does this compare with the acoustic features?

6) How do individual differences affect listeners' perceptions?

\section{Triangulation (stage 3):}

7) What acoustic features are perceived as particularly unpleasant? Do individual differences affect how acoustic features are perceived?

Finding answers to these questions contributes to a better understanding of the interrelated effects of guitar distortion and harmonic complexity and, as such, helps to gain insights into lower-level psychoacoustic features affecting the perception of distorted guitar tones among different groups of listeners.

\section{Method}

\section{Research materials}

To investigate the effects of guitar tone qualities on different chord structures, four guitar chords with fundamentals on the same root C3 $(263 \mathrm{~Hz})$ were recorded: 1. power chord; 2. major chord; 3. minor chord; 4. altered dominant chord (Figure 1). 


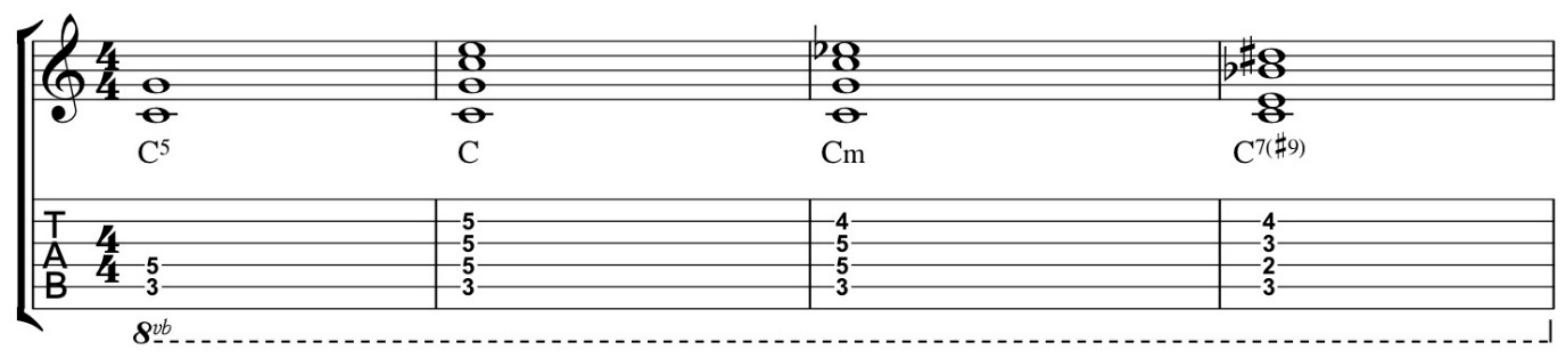

Figure 1. Voicings of the sample chords

Each chord was recorded with three guitars (Fender American Standard Stratocaster, Music Man John Petrucci, Gibson Les Paul Standard) to increase variance for the acoustic experiment. All guitars had humbucker pickups at the bridge position. The signals of three seconds in length were recorded in Apple Logic Pro X with a Roland OctaCapture audio-card and re-amped with a Palmer Daccapo box and five valve amplifiers: Laney GH50L, Marshall JCM2000 TSL100, Mesa Boogie Triaxis, Orange Dual Terror and Peavey 5150. These amplifiers covered a wide range of traditional and contemporary rock guitar tones. Transistor and modelling amplifiers were left out for two reasons. Firstly, because of their potentially different spectral and dynamic characteristics (Berger \& Fales, 2005, p. 185; Herbst, 2016, pp. 34-42), and secondly, because they are rather unpopular in many subgenres of rock music as a recent empirical study of 418 guitar players has demonstrated (Herbst, 2016, pp. 299-300).

All signals were recorded with three tone qualities: clean, overdrive and distortion. Until today, no agreement in the academic or professional community exists on the difference between overdriven and distorted guitar tones. In this study, distortion differed from overdrive simply in gain level. The gain differences were aurally similar from clean to overdrive and from overdrive to distortion to create comparable yet sufficiently different guitar tones. The signal ran into a Marshall 1960 cabinet with Celestion G12 Vintage 30 speakers and was recorded at $100 \mathrm{~dB}$ SPL, measured one meter away from the speaker, with a Shure SM57 dynamic microphone slightly off-center, on-axis and in close position. All recorded files were recorded at a sample rate of $44.1 \mathrm{kHz}$ and normalized in the audio export, meaning that the loudest peak was set at -.01 dBFS to compensate for the volume differences of the amplifier settings. However, the perceived loudness (RMS) was not affected as it largely depends on the compression and frequency spectrum of the signals. The total sample used for the acoustic analysis consisted of 180 audio files. For the listening test, the recordings produced with the combination of Stratocaster guitar and Laney amplifier ${ }^{2}$ were arranged in a Logic Pro project and exported as a single audio file.

${ }^{2}$ The equalization settings of the amplifier were all neutral $(=5)$, as was the Presence setting. Resonance was deactivated. Gain for the clean tone was at 3 with the Drive option deactivated. The overdriven tone had the same setting as the clean tone with the Drive increased to 7. To create the distorted tone, Drive was activated and set to 4 . 


\section{Acoustic experiment}

The acoustic features of the guitar samples were analyzed with Music Information Retrieval (MIR) technology using the MIR-Toolbox (Lartillot \& Toiviainen, 2007) version 1.6.1 and the Loudness-Toolbox (Genesis, 2009) version 1.2 in the MATLAB environment. The data produced by these toolboxes are abstract numbers rather than standardized units based on algorithmic calculations common in music informatics. The parameters to be extracted were chosen based on Terhardt's (1984) and Aures' (1985) model of sensory pleasantness. Terhardt (1984) presented a two-component concept of musical pleasantness consisting of musical harmony and sensory pleasantness. The affinity of tones, the interval relation as well as the compatibility of chords and melodic segments describe the harmonic element (Terhardt, 1984, pp. 278-279). Sensory pleasantness he defined "as the more or less complete lack of annoying features of a sound; it is pertinent to such sensory parameters as roughness and sharpness (i.e., on the physical side, amplitude fluctuations and presence of spectral energy at high frequencies)" (Terhardt, 1984, p. 282). Aures (1985) specified Terhardt's (1984) model by empirically extrapolating its four main components, roughness, sharpness, tonalness and loudness.

Roughness is considered the most important attribute for auditory dissonance in the paradigm of Helmholtz (1863) since it reduces a sound's smoothness by beatings of adjacent partials that excite the same critical band in the auditory system (Plomp \& Levelt, 1965). Thus, musical sounds with a rich harmonic spectrum are prone to produce roughness and spectral fluctuations (MacCallum \& Einbond, 2008, p. 203). Roughness was calculated with the MIR-Toolbox using two algorithms: Sethares' (1998) algorithm, henceforth termed 'roughness(s)', and a newer alternative algorithm by Vassilakis (2001), termed 'roughness(v)'. Both algorithms are included in the MIR-Toolbox. Additionally, spectral fluctuation strength was gathered with the MIRToolbox's function of calculating the distance between spectra of successive frames (Lartillot, 2014 , p. 60) as a third measure of roughness, termed 'roughness(flux)' henceforth. As one might expect, these three roughness measures correlated with each other, most strongly roughness(s) and roughness(v), $r(170)=.78, p<.01$, and roughness(s) and roughness(flux), $r(170)$ $=.61, p<.01$, and to a lesser effect roughness(v) and roughness(flux), $r(170)=.48, p<.01$ (all Bonferroni-corrected). That these correlations were not perfect supported the decision to keep alternative algorithms for roughness.

Zwicker and Fastl (2007, p. 245) advocate sharpness as the most important factor of sensory pleasantness. Sharpness can be computed by the spectral centroid as the mean frequency of the spectrum, measured in hertz (McAdams, Depalle \& Clarke, 2004, p. 191). A higher centroid caused by loud upper partials correlates with a brighter texture (Beauchamp, 1982; Schubert \& Wolfe, 2006; Wessel, 1979), which is likely to be perceived as unpleasant (Kidd \& Watson, 2003; Kumar, von Kriegstein, Friston, \& Griffiths, 2012) because the human ear is most sensitive in the range between $2 \mathrm{kHz}$ and $5 \mathrm{kHz}$ (Zwicker \& Fastl, 2007, pp. 17-22). Sharpness was measured by determining the spectral centroid with the MIR-Toolbox, concurring with empirical findings (Grey \& Gordon, 1978; Schubert \& Wolfe, 2006).

Loudness is a subjective parameter reducing sensory pleasantness related to the sensation of roughness and sharpness (Aures, 1985). It was calculated with the Loudness-Toolbox (Genesis, 2009) according to the ASNI S3.4-2007 norm (Moore, Glasberg \& Baer, 1997). Tonalness, defined by the "closeness of the partials to a harmonic series" (Sethares, 1998, pp. 79-80), is 
the only parameter in Terhardt (1984) and Aures' (1985) model increasing consonance. Its computational opposite is the inharmonicity algorithm, which can be executed by the MIRToolbox. However, since the tonalness and inharmonicity algorithms are only computationally correct for monophonic signals (Lartillot, 2014, pp. 143-144) and no available toolbox includes an alternative for polyphonic signals, tonalness was omitted in the analysis stage. The 180 audio files were analyzed using these five parameters: three roughness algorithms, sharpness, and loudness.

A Principal Component Analysis revealed that $78 \%$ of the total variance could be explained with just one component that includes all five parameters. To mitigate the high degree of correlation between the acoustic descriptors, a dimensional reduced parameter, henceforth abbreviated DRP, was created as an overall measure for sensorial unpleasantness. In addition, the separate parameters were considered to gain a more detailed understanding of how the individual psychoacoustic features are connected to the two primary variables of structural complexity and distortion level.

\section{Listening experiment}

The participants received an evaluation form on which they reported their gender, age and whether they were enrolled in a music-related study program. To capture individual differences, the preference for rock and heavy metal was assessed on a 5-point scale ( 1 = strong disliking; $5=$ strong liking). Moreover, the participants stated whether they played the electric guitar, and if they did, they provided information on their experience on the instrument $(0=$ no experience; $1=$ less than 2 years; 2 = less than 5 years; $3=$ more than 5 years). The audio examples were rated on a 10-point scale with labels on the anchors, signing left (1) as "unpleasant", and right (10) as "pleasant". The descriptor "pleasantness" was chosen over "consonance" to avoid a musical terminus, supported by research demonstrating affective labels helping non-musicians to rate chords (Halpern, Bartlett \& Dowling, 1998; Leaver \& Halpern, 2004). Furthermore, "pleasantness" complied with the terminology of the underlying theoretical framework by Terhardt (1984) and Aures (1985). Each chord played with every guitar tone quality was rated three times in a different random order to reduce unintentional order effects (Krumhansl, Bharucha \& Kessler, 1982; Juchniewicz \& Silverman, 2011). Having each chord rated three times also allowed testing robust scales rather than single items (Table 1).

Table 1. Psychometric properties of the electric guitar tones

\begin{tabular}{l|c|c|c|c|c|c|c} 
Guitar tones & $\begin{array}{c}\text { Cronbach's } \\
\alpha\end{array}$ & $\begin{array}{c}\text { Variance } \\
\text { explained }\end{array}$ & $M$ & Min & Max & Variance & $\begin{array}{c}\text { Number of } \\
\text { items }\end{array}$ \\
\hline Clean & .92 & $67 \%$ & 7.00 & 5.47 & 8.02 & 0.47 & 12 \\
Overdrive & .97 & $82 \%$ & 5.71 & 4.26 & 6.97 & 1.14 & 12 \\
Distortion & .97 & $88 \%$ & 4.72 & 3.25 & 6.29 & 1.43 & 12
\end{tabular}

The listening test was conducted in a group setting with 20 to 30 students and took approximately 15 minutes per session. The PI explained what would be happening without describing the intention of the experiment in detail so as not to influence the response behavior. Participants were free to cancel and leave the experiment. Prior to the rating, six of the sample chords 
were played to give an overall impression of the tone range. The participants then rated 36 stimuli: 12 per tone configuration (clean, overdrive, distortion), 9 per chord type (power, major, minor, dominant). These stimuli were played via a stereo system with two loudspeakers without a subwoofer. To reduce the likelihood of rating wrong chords, the samples were numbered and the number was announced before each stimulus was played. At the end of the listening test the participants were asked to state their reasons for the altered perception of the chords in writing.

171 students participated in the test, which took place at six German universities between 11 April and 13 May, 2016. The participants were aged between 18 and $39(M=22.06, S D=$ $3.33,53 \%$ women). $76 \%(N=127)$ were enrolled in a music-related study program, $95 \%(N=$ 163) were undergraduate students. On average, the students were in their second year of their undergraduate studies. $21 \%$ played the electric guitar and most who did (72\%) had played for more than five years. The mean preference for rock was $3.21(S D=1.33)$. In total, 6,156 chord ratings were obtained.

The effects of tone quality, chord structure and their interaction were analyzed with a repeated-measures ANOVA. The first factor was defined as guitar tone with the three levels: clean, overdriven and distorted. The second factor was chord structure with four levels of increasing harmonic complexity: power chord, minor chord, major chord and altered dominant chord. For both factors, the contrast was set to repeat.

The individual differences were tested with Univariate Analyses of Variance with the fixed factors gender, rock preference, guitar player and degree. Age was set as covariate. Bivariate correlational analyses were further calculated between individual factors and the three tone qualities, all Bonferroni-corrected. The participants' comments were categorized in the content analysis software MAQDA where the number of codes within each category was counted.

\section{Results}

\section{Acoustic experiment}

Analyzing musical structures required studying the role of the equipment to test its influence on the chords' acoustic features. The ANOVA demonstrated no significant acoustic differences between the three guitar models and the five amplifiers regarding the five acoustic parameters or the dimensionality reduced parameter (DRP). Therefore, no further consideration was given to the equipment.

According to theory, distortion should affect sensory pleasantness. An omnibus test (MANOVA) with the Tukey post hoc test was carried out with structure as the fixed factor to test whether the three guitar tone qualities differed for the combined DRP and individual parameters. The results confirmed that all tone qualities differed significantly from each other for the combined DRP, $F(2)=374.58, p<.001, \eta_{\mathrm{p}}{ }^{2}=.81$, as well as for all single parameters. The smallest effects were found for the three roughness values, roughness(s): $F(2)=114.70, p<$ $.001, \eta_{\mathrm{p}}{ }^{2}=.62$, roughness(v): $F(2)=77.46, p<.001, \eta_{\mathrm{p}}{ }^{2}=.47$, roughness(flux): $F(2)=157.74$, $p<.001, \eta_{\mathrm{p}}^{2}=.64$. Sharpness, $F(2)=286.48, p<.001, \eta_{\mathrm{p}}{ }^{2}=.76$, and loudness, $F(2)=380.97$, $p<.001, \eta_{\mathrm{p}}^{2}=.81$, exhibited greater variance as a result of increased distortion levels. Despite these differences between the individual parameters, the results clearly demonstrated that more distortion increased the sensorial unpleasantness of the stimuli. 
The relative impact of guitar tone and chord structure was estimated by categorical regression models for the DRP and each parameter (Table 2). Overall, the tone quality was significantly more influential than the structural complexity. Only on the individual parameters roughness(s), roughness(flux) and sharpness did the structure have a significant effect, most strongly on roughness(flux).

Table 2. Categorical regression models of the parameters of sensory pleasantness

\begin{tabular}{ll|rrr|rr|r} 
& & \multicolumn{3}{|c|}{ Coefficients } & ANOVA & Model \\
& & Beta & $F$ & Sig. & $F$ & Sig. & adj. $\mathrm{R}^{2}$ \\
\hline DRP & Structure & .09 & 2.71 & $\mathrm{~ns}$ & 121.51 & $<.001$ & .80 \\
& Tone & .89 & $2,249.17$ & $<.001$ & & & \\
\hline Roughness(s) & Structure & .18 & 16.83 & $<.001$ & 102.96 & $<.001$ & .70 \\
& Tone & .82 & 903.20 & $<.001$ & & & \\
Roughness(v) & Structure & .15 & 1.15 & $\mathrm{~ns}$ & 44.50 & $<.001$ & .49 \\
& Tone & .70 & 272.33 & $<.001$ & & & \\
Roughness(flux) & Structure & .42 & 151.62 & $<.001$ & 192.60 & $<.001$ & .84 \\
& Tone & .82 & 693.37 & $<.001$ & & & \\
\hline Sharpness & Structure & .20 & 38.96 & $<.001$ & 235.80 & $<.001$ & .80 \\
& Tone & .87 & $1,836.65$ & $<.001$ & & & \\
\hline Loudness & Structure & .09 & 2.27 & $\mathrm{~ns}$ & 236.36 & $<.001$ & .80 \\
& Tone & .89 & $2,446.89$ & $<.001$ & & & \\
\hline
\end{tabular}

Note: Parameters of sensory pleasantness were parametric, chord structure and guitar tone ordinal; $n s=$ not significant.

For determining the interrelation between structural complexity and tone quality related to sensory pleasantness, an omnibus test (MANOVA) was calculated with structure and tone set as fixed factors (Table 3). All roughness parameters ( $\mathrm{s} / \mathrm{v} /$ flux) showed interactions between chord structure and guitar tone. This result can be explained by the three parameters being connected to interval relations. In contrast, loudness and sharpness are mainly dependent on the amplifiers' settings, and therefore chord structure and guitar tone did not interact for these two parameters. For the DRP, no interaction effects could be confirmed; the guitar tone quality proved to be the relevant factor.

Table 3. Tests of between-subjects effects of the parameters of sensory pleasantness

\begin{tabular}{|c|c|c|c|c|c|c|c|c|c|c|c|c|}
\hline & \multicolumn{3}{|c|}{ Chord structure } & \multicolumn{3}{|c|}{ Guitar tone } & \multicolumn{3}{|c|}{$\begin{array}{c}\text { Interaction structure * } \\
\text { tone }\end{array}$} & \multicolumn{3}{|c|}{ Corrected Model } \\
\hline & df & $F$ & $\eta_{p}{ }^{2}$ & $\mathrm{df}$ & $F$ & $\eta_{p}^{2}$ & $\mathrm{df}$ & $F$ & $\eta_{\mathrm{p}}^{2}$ & $\mathrm{df}$ & $F$ & $\eta_{p}^{2}$ \\
\hline DRP & 3 & 5.20 & $.09 *$ & 2 & 394.61 & $.82 * * *$ & 6 & 0.48 & $.02^{\text {ns }}$ & 11 & 73.43 & $.83^{* * *}$ \\
\hline $\begin{array}{l}\text { Rough- } \\
\text { ness(s) }\end{array}$ & 3 & 8.50 & $.13 * * *$ & 2 & 175.22 & $.68 * * *$ & 6 & 3.47 & $.11 * *$ & 11 & 36.07 & $.70 * * *$ \\
\hline $\begin{array}{l}\text { Rough- } \\
\text { ness(v) }\end{array}$ & 3 & 8.43 & $.13 * * *$ & 2 & 94.75 & $.53 * * *$ & 6 & 3.87 & $.12 * *$ & 11 & 21.64 & $.59 * * *$ \\
\hline
\end{tabular}




\begin{tabular}{l|lrl|lll|lll|lll}
$\begin{array}{l}\text { Rough- } \\
\text { ness(flux) }\end{array}$ & 3 & 131.73 & $.70^{* * *}$ & 2 & 596.57 & $.88^{* * *}$ & 6 & 17.70 & $.39^{* * *}$ & 11 & 154.05 & $.91^{* * *}$ \\
\hline Sharpness & 3 & 19.10 & $.25^{* * *}$ & 2 & 380.39 & $.82^{* * *}$ & 6 & 1.62 & $.06^{\text {ns }}$ & 11 & 75.26 & $.83^{* * *}$ \\
\hline Loudness & 3 & 5.73 & $.09^{* *}$ & 2 & 404.83 & $.83^{* * *}$ & 6 & 0.49 & $.02^{\text {ns }}$ & 11 & 75.43 & $.83^{* * *}$
\end{tabular}

Note: $n s=$ not significant, ${ }^{* *} p<.01, * * * p<.001, N=180$.

To briefly summarize, the acoustic analysis confirmed the theoretical expectations. Each increase in gain level, from clean to overdrive and from overdrive to distortion, had significant effects on sensory pleasantness. The effect of tone quality was significantly stronger than that of structural complexity; however, the three roughness ( $\mathrm{s} / \mathrm{v} / \mathrm{flux})$ parameters crucial in dissonance theory showed interaction effects between structure and tone. Spectral fluctuation strength (roughness flux) was interrelated most closely with chord structures.

\section{Listening experiment}

Research on distorted guitar chords and rock harmony has found power and major chords to be the chords most commonly used in rock music. The descriptive values (Table 4, Figure 2) of the listeners' ratings confirm that these two chords were perceived as most pleasant among the four chords irrespective of guitar tone.

Table 4. Descriptive statistics of chord ratings with different guitar tones

\begin{tabular}{lcccc} 
& Power chord & Major & Minor & Altered dominant \\
& $M(S D)$ & $M(S D)$ & $M(S D)$ & $M(S D)$ \\
\hline Clean & $7.40(1.48)$ & $7.52(1.46)$ & $6.96(1.60)$ & $6.06(2.04)$ \\
Overdrive & $6.76(1.97)$ & $6.64(2.03)$ & $5.05(2.22)$ & $4.40(2.26)$ \\
Distortion & $6.06(2.48)$ & $5.61(2.59)$ & $3.89(2.52)$ & $3.35(2.46)$
\end{tabular}

Note: 1 denotes a most unpleasant, 10 a most pleasant rating

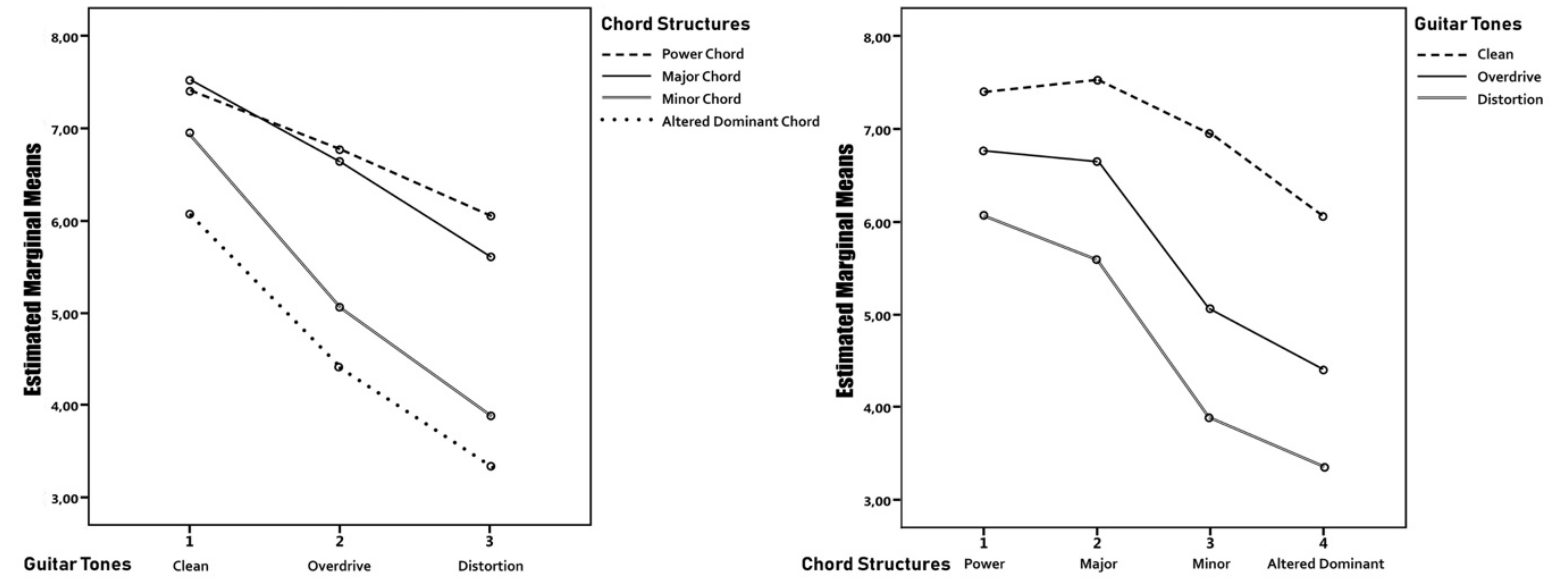

Figure 2: Influence of guitar tones on the ratings of chord structures

To quantify the within-subjects effects of guitar tone and chord structure, a repeated-measures ANOVA was calculated. The test (Greenhouse-Geisser corrected) revealed a strong effect of 
guitar tone, $F(2,1,215)=150.67, p<.001, \eta^{2} \mathrm{p}=.47$, and an even stronger effect of structure, $F(3,1,671)=267.22, p<.001, \eta^{2} \mathrm{p}=.61$. Both variables interacted with a medium to strong effect, $F(6)=53.38, p<.001, \eta^{2}=.24$, which could be expected based on the underlying theory of rock harmony and the effects of guitar distortion.

The tests of within-subjects contrasts (Table 5) demonstrated a stronger effect between overdriven and distorted guitar tones than between clean and overdriven tones. The power and major chords differed significantly, if only with a weak effect. The ratings between all other chords differed much more. The biggest difference was between major and minor chords, supporting the claims of harmonicity or tonalness, whereby the major chord as the chord with closer concordance to the harmonic series should be more pleasant. The altered dominant chord, containing both a major third and a minor third in disguise (augmented ninth) as well as the dissonant tritone interval, was perceived as the most unpleasant chord.

The interaction between guitar tone and chord structure demonstrated that the differences between the chord ratings were greater when adding overdrive to a clean signal than when shifting from overdrive to distortion. Overdriving a clean signal changed the perceived pleasantness between major and minor chords the most. Adding distortion to an overdriven signal only affected the relation between power and major chords; the preference for the distorted power chord increased.

Table 5. Tests of within-subjects contrasts of guitar tones and chord structures

\begin{tabular}{|c|c|c|c|c|c|}
\hline Effect & & & $\mathrm{F}$ & Sig. & $\eta_{\mathrm{p}}^{2}$ \\
\hline \multirow[t]{2}{*}{ Tones } & clean vs. overdrive & & 98.13 & $<.001$ & .37 \\
\hline & overdrive vs. distortion & & 178.78 & $<.001$ & .51 \\
\hline \multirow[t]{3}{*}{ Structures } & & power chord vs. major & 10.66 & .001 & .06 \\
\hline & & major vs. minor & 237.66 & $<.001$ & .58 \\
\hline & & minor vs. dominant & 99.90 & $<.001$ & .37 \\
\hline Tones * & clean vs. overdrive & power chord vs. major & 10.68 & .001 & .06 \\
\hline \multirow[t]{5}{*}{ Structures } & & major vs. minor & 91.34 & $<.001$ & .35 \\
\hline & & minor vs. dominant & 6.63 & .01 & .04 \\
\hline & overdrive vs. distortion & power chord vs. major & 28.15 & $<.001$ & .14 \\
\hline & & major vs. minor & 2.05 & .15 & .01 \\
\hline & & minor vs. dominant & 2.27 & .13 & .01 \\
\hline
\end{tabular}

Considering individual differences, men $(M=3.40, S D=1.33)$ and women $(M=3.04, S D=$ 1.31) did not differ significantly in their preference for rock, $t(170)=-1.76 ; p=.08 ; d=0.27$. Electric guitar players $(M=4.03, S D=1.20)$ showed a significantly higher liking for rock music than participants who did not play the instrument $(M=3.00, S D=1.28), t(170)=4.46 ; p<.01$; $d=0.83$. Furthermore, guitar playing experience correlated with rock preference $\left(r_{s}(171)=.31\right.$; $p<.01)$. Such individual differences did not significantly affect the ratings of the clean tone, $F(18,163)=1.22, p=.25, \eta_{\mathrm{p}}^{2}=.02$, but they did so in the cases of overdriven and distorted tones, as the tests of between-subjects effects demonstrate (Table 6). The results of the overdriven and distorted tones were similar with effects slightly stronger for distorted tones. Whether or not participants were enrolled in a music-related study program proved insignificant. Men and women did not differ significantly in their liking of overdriven and distorted tones. The decisive factor for liking overdriven and distorted tones was a preference for rock 
music, but age and being an electric guitarist played a minor role, too. Despite gender being statistically insignificant, it was part of a three-way-interaction with rock preference and being an electric guitar player. As the sociodemographic data and correlational analyses (in the next paragraph) show, the women of this sample were less likely to play electric guitar and listen to rock music, which might explain the interaction effect.

Table 6. Tests of between-subjects effects for overdriven and distorted guitar tones

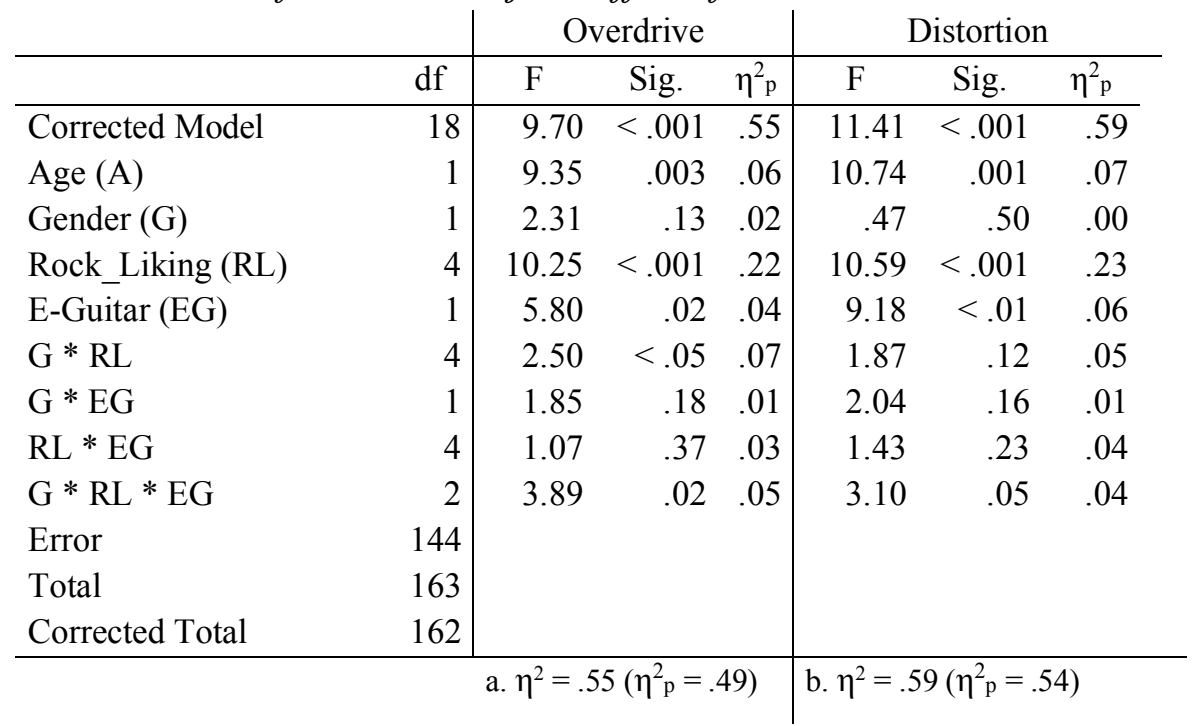

Subsequent correlational analyses (Bonferroni corrected) confirmed that a preference for rock showed a strong positive association with valence ratings for overdriven, $r(171)=.67, p<.01$, and distorted, $r(171)=.69, p<.01$, tones. For many rock enthusiasts, overdrive and distortion did not reduce the pleasantness of the guitar chords, whereas for many not preferring this genre, overdriven and distorted tones were felt as unpleasant. Older participants showed a higher liking of overdriven, $r(161)=.29, p<.01$, and distorted, $r(161)=.32, p<.01$, chords, as did electric guitar players, overdrive: $r(171)=.27, p<.01$ (guitar players: $M=6.66, S D=1.73$; non-guitar players: $M=5.34, S D=1.98$ ), distortion: $r(171)=.33, p<.01$ (guitar players: $M=$ $6.26, S D=2.12$; non-guitar players: $M=4.33, S D=2.30)$. Furthermore, the guitar playing experience increased the liking of overdriven $\left(r_{s}(171)=.28 ; p<.01\right)$ and distorted sounds $\left(r_{s}(171)=.33 ; p<.01\right)$, but it proved insignificant with clean sounds, $r_{s}(171)=-.01 ; p=.88$. Although gender differences were not reported in the ANOVA, correlational analyses revealed some tendencies. While the difference regarding overdriven tones was small with men showing a higher liking of it, $r(171)=.17, p<.05$ (men: $M=5.97, S D=2.00$; women: $M=5.30, S D=$ 1.96), the gender difference increased with the distorted tone, $r(171)=.26, p<.01$ (men: $M=$ 5.38, $S D=2.37$; women: $M=4.16, S D=2.16$ ).

154 of the 171 participants answered the question regarding the reasons for their perceptions. 250 codes were allocated to four main categories (Table 7). Within "sound characteristics", most of the statements addressed issues related to frequency. Besides an unbalanced sound, sharpness caused by unpleasant treble frequencies resulting from distortion was emphasized. Other parameters of the psychoacoustic framework such as clarity, roughness and loudness were also highlighted. 
Table 7. Category system of the qualitative answers

\begin{tabular}{|c|c|c|c|}
\hline $\begin{array}{l}\text { 1. Sound characteristics } \\
(\mathrm{N}=151 ; 60 \%)\end{array}$ & $\begin{array}{l}\text { 2. Listening habits } \\
(\mathrm{N}=55 ; 22 \%)\end{array}$ & $\begin{array}{l}\text { 3. Effects and associations } \\
(\mathrm{N}=24 ; 10 \%)\end{array}$ & $\begin{array}{l}\text { 4. Context } \\
(\mathrm{N}=20 ; 8 \%)\end{array}$ \\
\hline $\begin{array}{ll}\text { - } & \text { Frequency }(\mathrm{n}=60) \\
& (30 \text { tone balance, } 18 \\
& \text { unpleasant treble, } 12 \\
& \text { clanging sound }) \\
\text { - } & \text { Clarity }(\mathrm{n}=36) \\
\text { - } & \text { Naturalness }(\mathrm{n}=16) \\
\text { - } & \text { Beats }(\mathrm{n}=11) \\
\text { - } & \text { Loudness }(\mathrm{n}=11) \\
\text { - } & \text { Longer decay time (n } \\
& =8) \\
\text { - } & \text { Noise }(\mathrm{n}=9)\end{array}$ & $\begin{array}{l}\text { - General listening hab- } \\
\text { its }(\mathrm{n}=44) \\
\text { - Instrumental back- } \\
\text { ground }(\mathrm{n}=11)\end{array}$ & $\begin{array}{l}\text { - } \quad \text { Effects }(\mathrm{n}=17) \\
\text { - }\end{array}$ & $\begin{array}{l}\text { - } \quad \text { Context in the song } \\
(\mathrm{n}=10) \\
\text { - } \quad \text { Test situation }(\mathrm{n}=10)\end{array}$ \\
\hline
\end{tabular}

Most statements within the second category suggest habits affecting the perception. A few participants claimed that their hearing of distorted chords differed from that of electric guitar players. Others explained instrumental or musical socializations hampering their liking of the distorted guitar. Some rock listeners stressed having acquired a high tolerance of dissonant or harsh sounds since they were accustomed to distorted tones. The third category comprised perceived effects and emotions, mostly described with negative attributes such as exhaustion, painfulness, aggressiveness, menace, inner disturbance, hardness, coldness or emotions such as fear. Statements on associations were less negative and included references to songs, music genres, persons or situations. In the fourth category, the need for a larger musical context was stressed to be able to rate the guitar tones adequately.

\section{Data triangulation}

Using the same stimuli in both parts of the experiment permitted data correlation (Bonferronicorrected) of their results. Correlating the dimensionality reduced parameter (DRP) with the listener ratings confirmed an overall negative effect of increasing distortion levels on perceived pleasantness, $r_{s}(171)=-.67, p<.01$. This effect was weaker for participants who were fans of rock music (preference rating 3 to 5 ), $r_{s}(70)=-.51, p<.05$, than for those stating not to like rock music (preference rating 1 and 2 ), $r_{s}(84)=-.72, p<.01 .^{3}$ Women, $r_{s}(91)=-.71, p<.01$, were affected more strongly by the increased sensorial unpleasantness resulting from guitar distortion than men, $r_{s}(80)=-.55, p<.01$. The largest difference was between those participants not playing the electric guitar, $r_{s}(136)=-.69, p<.01$, and electric guitar players, $r_{s}(35)=-.15$, $p=.39$, who were not significantly affected by the introduction of sensorial unpleasantness from distortion.

${ }^{3}$ The preference for rock music was split into two groups to be able to compare rock fans with participants who do not like this genre. Furthermore, the data format of the two experiments did not allow direct correlations but required data to be processed and entered into a third project, making it impossible to keep interval-scaled, person-related data. 
To better understand how acoustic features affect different groups of listeners, the five individual parameters were also correlated (Bonferroni-corrected) with the total listener sample. In accordance with the psychoacoustic model, all parameters reduced the pleasantness of the chords. Roughness(s) correlated with the listeners' ratings the weakest, $r_{s}(171)=-.41, p<.05$, followed by roughness $(\mathrm{v}), r_{s}(171)=-.56, p<.01$. In contrast, roughness(flux) had an almost perfect negative correlation, $r_{s}(171)=-.90, p<.01$. Strong effects of sharpness, $r_{s}(171)=-.74$, $p<.01$, and loudness, $r_{s}(171)=-.67, p<.01$, were also confirmed to reduce pleasantness.

Apart from these single parameters, Spearman correlation demonstrated an overall close connection between perceived pleasantness and structural complexity, $r_{s}(171)=-.63, p<.001$, and between pleasantness and tone quality, $r_{s}(171)=-.72, p<.001$. More complex chords and greater distortion levels had a negative effect on sensory pleasantness for many listeners.

\section{Discussion}

\section{Influence of tone quality and structural complexity on acoustic features and listener percep- tions of guitar chords}

Based on previous theoretical and spectral-analytical research (Berger \& Fales, 2005; Herbst, 2016; Lilja, 2005, 2015; Walser, 1993), both overdrive and distortion were expected to alter the acoustic properties of guitar chords and amplify unpleasant features. As the results have shown, each increase in gain level, from clean to overdrive and from overdrive to distortion, significantly reduced sensory pleasantness (Aures, 1985; Terhardt, 1984). The dimensionality reduced parameter (DRP) and all individual parameters were influenced by tone quality the most. For loudness, this can be explained by distortion's characteristic compression effect which results from the limited waveform (Berger \& Fales, 2005, p. 184). Increased sharpness may have resulted from distortion's characteristic feature of enriched spectral content (Herbst, 2016, pp. 120-127), which is prone to produce roughness (MacCallum \& Einbond, 2008, p. 203) and harshness (Grey \& Gordon, 1978; Zwicker \& Fastl, 2007, p. 245). In this context, the relevance of the vibration behavior of the string must be considered. The string's bending stiffness, gauge and winding lead to additional inharmonic spectra with frequencies that differ by a few hertz from the frequencies of the fundamental notes and their harmonic partials (Zollner, 2014, pp. 10-222-224). This inharmonicity, combined with distortion, produces a harsher sound. Moreover, the beats of close frequencies result in roughness and amplitude fluctuations that are perceived as periodic "pseudo-noise" (Zollner, 2014, pp. 10-224). With these timbral alterations, the distorted tone is noisier, rougher and more present than a clean sound (Berger \& Fales, 2005, p. 184; Herbst, 2016, pp. 129-134). Spectral fluctuation (roughness flux) was the parameter with the strongest interaction between guitar tone and chord structure. It can be assumed that interval changes affect the beatings of adjacent bands in the auditory system (Helmholtz, 1863; Plomp \& Levelt, 1965), and that the enriched spectrum with extended harmonic and nonharmonic components will enhance this effect, as described by Aures (1985).

The acoustic experiment gave indications that tone quality had a much greater impact than chord structure on expected sensory pleasantness. The theoretical framework (Aures, 1985; Terhardt, 1984) specifies neither the relative impact of structure and tone nor of individual psychoacoustic parameters, for instance whether sharpness influences the perception equally to loudness. The data triangulation in the present study demonstrated that roughness(flux) was the 
parameter affecting perception the most, followed by sharpness and loudness; the more traditional roughness $(\mathrm{s} / \mathrm{v})$ algorithms correlated least strongly. Correlational analyses of the triangulated data showed tone quality $\left(r_{s}=-.72\right)$ to affect the perceived pleasantness slightly more than structural complexity $\left(r_{s}=-.63\right)$. This result concurs with Virtala et al.'s $(2018$, p. 325) recent neurocognitive study on distorted guitar chords, in which brain activity was found to react stronger to tone qualities than to chord structures. The listening test revealed that both tone quality $\left(\eta_{p}^{2}=.47\right)$ and structural complexity $\left(\eta^{2}=.61\right)$ have great effect on the listener, with the effect of structure being stronger. These outcomes, even if deviating, are not contradictory and more a question of relative impact. What is more important, the data suggests that tone quality and structural complexity strongly affect the perception, and that the effect is enhanced by interactions between these two variables.

Reflecting on the parameters of sensory pleasantness, roughness(s/v), the main factor in consonance theory in Helmholtz' (1863) tradition, did not appear an optimal indicator for dissonance. Discussing roughness, Parncutt (2006, pp. 205-206) claimed the clear identifiability of the root to be the decisive factor of consonance, highlighting the importance of tonalness. Evidence for this argument was found in the participants' statements stressing that distortion reduces transparency and clarity. This further accords with the relevance of harmonicity described by McDermott et al. (2010), supporting Aures' (1985) parameter of tonalness. It also conforms with Czedik-Eysenberg et al.'s (2017) study according to which tonalness has a significant effect on perceived "hardness", a concept that might be related to sensory unpleasantness. In the case of the electric guitar, spectral fluctuation strength (roughness flux), in combination with loudness, is likely to be the key contributor to sensory unpleasantness. The natural fluctuations resulting from interval relations are increased by distortion's compression effect, accentuating the uneven envelope by acceleration and greater density, ultimately diminishing the chord's sonority. In the listening test, spectral fluctuation demonstrated its central role by an almost linear negative correlation with the ratings of pleasantness. Loudness was confirmed as another decisive factor. This result accords with Czedik-Eysenberg et al.'s (2017) study that found spectral fluctuations, sharpness and high loudness to contribute to perceived hardness. Sharpness clearly affected sensory pleasantness, as evidenced by the strong correlation between acoustic data and subjective ratings. For many participants disliking distorted tones, sharpness was the decisive parameter for their rating. The open answers described unpleasant treble frequencies causing physical pain, which can be explained by the ear's sensitivity in the frequency range between $2 \mathrm{kHz}$ and $5 \mathrm{kHz}$ (Zwicker \& Fastl, 2007, pp. 17-22). This finding contributes to the body of literature on the negative effect of sharp timbres on perceived pleasantness (Kidd \& Watson, 2003; Kumar et al., 2012). Overall, sharpness and loudness seem to be reliable predicators for the impact of tone quality, whereas roughness(flux) is better suited to predict the effect of structure while still being determined by tone quality primarily.

\section{Pleasantness of guitar chords with different tone qualities}

The main research interest concerned the prevalence of power and major chords in rock harmony with the underlying assumption that overdriven and distorted tones increase lower-level psychoacoustic features, resulting in high degrees of unpleasantness of the harmonically more complex minor and dominant chords. Not considering individual differences and other aspects of musical context, the results clearly showed that power and major chords were perceived as 
significantly more pleasant than minor and altered dominant chords. In line with the theoretical and spectral-analytical findings of Lilja $(2005,2015)$ and Herbst $(2016)$, this gap enlarged with increased levels of distortion. Furthermore, while the major chord was perceived as more pleasant than the power chord when played with a clean tone, the preference for the power chord superseded the major chord with an overdriven tone, and even more so with a distorted tone. These results concur with musical practice within rock genres. In less distorted rock styles, such as blues rock or classic rock, major chords are frequently used (Cope, 2010; De Clercq \& Temperley, 2011; Lilja, 2015), whereas in heavily distorted metal genres, most riffs are limited to power chords (Berger \& Fales, 2005; Herbst, 2016; Moore, 2001; Walser, 1993). Minor chords are rarely played (De Clercq \& Temperley, 2011; Lilja, 2005, p. 20), except in styles such as black metal that deliberately intend to create an unpleasant sound (Hagen, 2011; Reyes, 2013). Such sounds, however, can still be appealing to listeners for aesthetic, musical or social reasons (Berger, 1999; Hagen, 2011; Reyes, 2013).

Although not a primary concern in the present study, the result that there is a perceptual difference between power and major chords opposes Lilja's (2015) theory of both chords being perceptually identical. This finding accords with Virtala et al.'s (2018) neurocognitive study suggesting differences in brain activity between the two chords. However, the similar ratings of these two chords support Juchniewicz and Silverman's (2011) and Lilja's (2015) claim of distorted power chords having a latent major character. Nonetheless, power and major chords are neither acoustically nor perceptually identical when played with distortion.

Previous research has argued that noisy timbres relate to high arousal and low valence (Arnal et al., 2015; Johnstone \& Scherer, 1999; Mende et al., 1990). Wallmark et al. (2018, p. 345) recently reported that listeners perceived noisy guitar tones as physically effortful, associated them with anger and fear, and generally disliked such timbres. The results of this study point in the same direction. Although perceived exertion was not captured, higher levels of distortion were generally perceived as unpleasant. The open answers in the listening test further demonstrated negative connotations such as exhaustion, painfulness, aggressiveness, menace, inner disturbance, hardness, coldness or emotions such as fear that support Wallmark et al.'s (2018) quantitative results. Harsh and rough tones, identified as key parameters for negative valence by the research group (Wallmark et al., 2018), were among the main features found during the qualitative analysis in this study. However, these were only expressed by participants who did not play the electric guitar and who did not like rock music. In other words, mainly classically socialized musicians.

\section{Individual differences}

In previous research on the perception of guitar distortion, individual differences have rarely been considered. However, genre, culture, musical training, personality, musical preferences, listening context and sociodemographic factors affect the emotional judgment and preference of sounds (Ladinig \& Schellenberg, 2012; McLachlan et al., 2013; Vuoskoski et al., 2012). The results of this study confirm the relevance of some individual differences.

Although being a guitar player was irrelevant in Juchniewicz and Silverman's (2011) study, the expectation that a familiarity with the instrument and its tonal palette (Wallmark et al., 2018) might play a role for the perception of guitar chords proved right. Electric guitar players 
showed greater preference for distorted tones and playing experience correlated with pleasantness. The triangulation results clearly demonstrated that electric guitar players did not perceive distorted sounds to be as unpleasant as the average sample population. This supports the notion of instrumental experience affecting the perception of that instrument's sound and the structures being played on it (Ladinig \& Schellenberg, 2012; Margulis, Mlsna, Uppunda, Parrish \& Wong, 2009; Vuoskoski et al., 2012). The results also oppose studies that found no difference in the perception of short sound stimuli between musicians and non-musicians or different instrumentalists (Filipic, Tillmann \& Bigand, 2010).

Although the relevance of guitar playing experience might indicate an effect of musical education, being enrolled in a music-related study program proved irrelevant. This result is in line with Juchniewicz and Silverman's (2011) study that did not find ear training experience to affect the tonality perception of distorted power chords. Considering the predominant classical socialization of the participants in the music programs, this result can most likely be explained by the musicians' preference of classical music and related instruments (Virtala et al., 2018, p. 328).

The influence of an affinity with rock music was confirmed as a main factor for different perceptions of distorted guitar chords. In the listening test, this individual factor was the primary indicator for perceived pleasantness of overdriven and distorted guitar chords, which accords with the growing body of research that sees affective responses linked to musical genres and expertise (Gold, Frank, Bogert \& Brattico, 2013; Müllensiefen, Gingras, Musil \& Stewart, 2014; Roberts, 1986; Virtala \& Tervaniemi, 2017, pp. 396-398). Participants with a preference for rock music not only rated all chords as more pleasant, they were also the only ones not significantly affected by increasing levels of distortion and more complex chord structures. Just as Berger (1999, pp. 215-218) found metal musicians perceiving musical structures differently from Western music theory, it appears that rock fans perceive distorted tones differently from people who do not like this genre (Virtala \& Tervaniemi, 2017, p. 398). This result accords with studies that demonstrated that characteristic musical features of certain genres are processed differently by musicians specializing in other genres (Tervaniemi, Janhunen, Kruck, Putkinen \& Huotilainen, 2015; Vuust, Brattico, Seppänen, Näätänen \& Tervaniemi, 2012). However, the triangulation results showed that while rock fans were less affected by the increased sensory unpleasantness of distortion than participants who do not like this genre, they still differed considerably from electric guitar players. This raises a question for future research as to the relative impact of genre preferences, instrument choice and playing experience.

Age influenced the perception of overdriven and distorted tones significantly. Older participants showed a higher tolerance of unpleasant sounds. Although it might be assumed that they were socialized at a time when rock music was highly popular, representative data from the German Music Information Centre (MIZ, 2018) shows that people in Germany between 14 and 39 share the same affinity for the rock genre. Therefore, it is questionable whether familiarization (McLachlan et al., 2013) with distorted guitar tones can account for the effect of age.

Gender was a factor with no clear result. Although the ANOVA did not report significant differences, correlational analyses indicated that men were more tolerant of distorted guitar tones. This was confirmed by the results of data triangulation, which showed that women were more affected by the strengthened sensorial unpleasantness of guitar distortion than were men, concurring with the findings of Eysenberg et al. (2017) on musical "hardness". 


\section{Methodical limitations}

The generalizability of the results is subject to certain limitations. To fully operationalize Terhardt (1984) and Aures' (1985) model of sensory pleasantness, tonalness would have to be included. Since it could not be measured with the two toolboxes used in this study, it may be that structural complexity on an acoustic level was captured insufficiently, thus underestimating its effect. This was partly mitigated through the listening test, which was not dependent on such a psychoacoustic operationalization. Another limitation is the sample, which cannot be considered representative as only students with an affinity for music were recruited. Moreover, the apparent topic of the study might have led participants to exaggerate their responses, for instance rock enthusiasts wanting to express their preference for edgier experiences, whereas participants disliking the genre may have over-emphasized their dislike of rock-music-related dissonance strongly associated with distorted guitar tones. A further restriction was the experimental setting differing from real-world perceptions, raising questions of ecological validity as indicated in the participants' comments. Short samples were compared without any musical context. Isolated sounds that were rated as rather unpleasant might have been interesting in an actual rock song. Furthermore, issues of aesthetics and related socio-cultural aspects were ignored and merely considered in the reductive form of a preference for rock.

Other factors to be considered include audio engineering with pivotal aspects such as microphone choice and placement. While the Shure SM57 is an industry standard and thus contributes to capturing an authentic guitar sound, it must be stated that this microphone boosts the signal in the frequency range between 2 and $5 \mathrm{kHz}$, exactly the range in the human hearing perceived as most unpleasant. Similar to the microphone itself, its position plays a role. The audio recordings for this study were produced with an off-center, on-axis position, emphasizing the low-end in relation to the presence range. Interpreting the results with a real-world scenario in mind would require considering the microphone position because a more on-center or offaxis placement would enhance the frequencies contributing to sharpness considerably. Even the distance between the microphone and the loudspeaker affects the tone balance (Herbst 2017). To further consider the real-world meaning of the results, sound processing by a live or studio mixing engineer can either reduce or boost unpleasant sound features not only through equalization but also by volume compression, modulation effects and further instrument layers (Mynett 2017). Therefore, several negative acoustic features investigated in this study can be attenuated or emphasized by audio processing techniques.

\section{Conclusion}

This study explored the interrelated effects of distortion and harmonic structure on acoustic features and the perceived pleasantness of electric guitar chords to better understand the prevalence of power and major chords in many subgenres of rock music from a psychoacoustic perspective. The results suggest that simple chord structures close to the harmonic series produce fewer acoustic features that are likely to be perceived as unpleasant when distortion levels are increased. This might indeed help explain the common use of simple chords played in rock music with distorted guitars on the lower level of psychoacoustic features. However, explaining the choice of chords in rock music practice will require further research that includes higher level aspects such as semantics, sociocultural aspects and a better ecological validity with more 
authentic stimuli together with wider musical contexts. Nonetheless, based on the results of this study, one wonders why the canonical rock harmony has largely passed on a broader variety of chords when rock enthusiasts generally show a high level of tolerance of complex chord structures even when played with highly distorted guitar tones. Qualitative research might be valuable to answer such questions about musical practice.

\section{References}

Arnal, L. H., Flinker, A., Kleinschmidt, A., Giraud, A.-L., \& Poeppel, D. (2015). Human screams occupy a privileged niche in the communication soundscape. Current Biology, 25, 2051-2056.

Aures, W. (1985). Der sensorische Wohlklang als Funktion psychoakustischer Empfindungsgrößen. Acustica, 58, 282-290.

Baugh, B. (1993). Prolegomena to Any Aesthetics of Rock Music. The Journal of Aesthetics and Art Criticism, 51(1), 23-29.

Beauchamp, J. (1982). Synthesis by spectral amplitude and 'brightness' matching of analyzed musical instrument tones. Journal of Audio Engineering Society, 30, 396-406.

Belz, C. (1972). The story of Rock. 2. ed. New York: Oxford University Press.

Berger, H. M. (1999). Metal, Rock, and Jazz. Perception and Phenomenology of Musical Experience. Hanover: Wesleyan University Press.

Berger, H. M., \& Fales, C. (2005). 'Heaviness' in the Perception of Heavy Metal Guitar Timbres. The Match of Perceptual and Acoustic Features over Time. In P. D. Greene, \& T. Porcello (Eds.), Wired for sound. Engineering and technologies in sonic cultures (pp. 181-197). Middletown: Wesleyan University Press.

Cope, A. L. (2010). Black Sabbath and the Rise of Heavy Metal Music. Farnham: Ashgate.

Covach, J., \& Boone, G. (Eds.) (1997). Understanding Rock: Essays in Musical Analysis. Oxford: Oxford University Press.

Czedik-Eysenberg, I., Knauf, D., \& Reuter, C. (2017). Was macht Musik "hart”? Klangliche Merkmale zur genreübergreifenden Identifikation musikalischer Härte. Fortschritte der Akustik. DAGA $2017,43^{\text {th }}$ German annual conference for Acoustics. Kiel, 186-189. Retrieved from http://homepage.univie.ac.at/christoph.reuter/DGM2013/DAGA2017 Paper_Czedik-Eysenberg_Knauf Reuter.pdf. Accessed 8 June 2018.

De Clercq, T., \& Temperley, D. (2011). A corpus analysis of rock harmony. Popular Music, 30(1), $47-70$.

Elliott, T., Hamilton, L. S., \& Theunissen, F. E. (2013). Acoustic structure of the five perceptual dimensions of timbre in orchestral instrument tones. Journal of the Acoustical Society of America, $133,389-404$.

Everett, W. (2004). Making sense of rock's tonal systems. Music Theory Online, 10. Retrieved from http://www.mtosmt.org/issues/mto.04.10.4/mto.04.10.4.w_everett.pdf. Accessed 8 June 2018.

Everett, W. (Ed.) (2008). Expression in Pop-Rock Music: Critical and Analytical Essays. London: Routledge.

Filipic, S., Tillmann, B., \& Bigand, E. (2010). Judging familiarity and emotion from very brief musical excerpts. Psychonomic Bulletin and Review, 17(3), 335-341. 
Frith, S. (1996). Performing Rites. On the Value of Popular Music. Cambridge: Harvard University Press.

Genesis (2009). Loudness Toolbox. Retrieved from http://genesis-acoustics.com/en/loudness_online32.html. Accessed 8 June 2018.

Gold, B. P., Frank, M. J., Bogert, B., \& Brattico, E. (2013). Pleasurable music affects reinforcement learning according to the listener. Frontiers in Psychology, 4, 00541. DOI: 10.3389/fpsyg.2013.00541

Goyke, K. N., Altenmüller, E., Möller, J., \& Münte, T. (2004). Changes in emotional tone and instrumental timbre are reflected by the mismatch negativity. Cognitive Brain Research, 21, 351-359.

Gracyk, T. (1996). Rhythm and noise: An aesthetics of rock. Durham: Duke University Press.

Grey, J. M., \& Gordon, J. W. (1978). Perceptual effects of spectral modifications on musical timbres. The Journal of the Acoustical Society of America, 63(5), 1493-1500.

Hagen, R. (2011), 'Musical style, ideology, and mythology in Norwegian black metal', in J. Wallach, H. M. Berger, \& P. D. Greene (Eds.), Metal rules the globe. Heavy metal music around the world (pp. 180-199). Durham: Duke University Press.

Halpern, A. R., Bartlett, J. C., \& Dowling, W. J. (1998). Perception of mode, rhythm, and contour in unfamiliar melodies: Effects of age and experience. Music Perception, 15, 335-355.

Helmholtz, H. v. (1863). On the Sensations of Tone as a Physiological Basis for the Theory of Music. 6. ed., 1913. Braunschweig: Vieweg.

Herbst, J.-P. (2016). Die Gitarrenverzerrung in der Rockmusik. Studien zu Spielweise und Ästhetik. Münster: LIT.

Herbst, J.-P. (2017). Historical development, sound aesthetics and production techniques of the distorted electric guitar in metal music. Metal Music Studies, 3(1), pp. 24-46.

Holm-Hudson, K. (Ed.) (2002). Progressive Rock Reconsidered. London: Routledge.

Johnstone, T., \& Scherer, K. R. (1999). The effects of emotions on voice quality. Proceedings of the 14th International Congress of Phonetic Sciences (pp. 2029-2032). San Francisco, CA: ICPS.

Juchniewicz, J., \& Silverman, M. J. (2011). The influence of progression type and distortion on the perception of terminal power chords. Psychology of Music, 41(1), 119-130.

Juslin, P. N. (2000). Cue utilization in communication of emotion in music performance: Relating performance to perception. Journal of Experimental Psychology: Human Perception and Performance, 26, 1797-1813.

Juslin, P. N., \& Laukka, P. (2003). Communication of emotions in vocal expression and music performance: Different channels, same code? Psychological Bulletin, 129, 770-814.

Kendall, R. A. (2002). Music Experiment Development System (MEDS) (Version 2002-B-1).

Kendall, R. A., \& Carterette, E. C. (1996). Difference thresholds for timbre related to spectral centroid. In B. Pennycook \& E. Costa-Giomi (Eds.), Proceedings of the 4th International Conference for Music Perception and Cognition (pp. 91-95). Montreal, Canada: ICMPC.

Kidd, G. R., \& Watson, C. S. (2003). The perceptual dimensionality of environmental sounds. Noise Control Engineering Journal, 51, 216-231.

Krumhansl, C. L., Bharucha, J. J., \& Kessler, E. J. (1982). Perceived harmonic structures of chords in three related musical keys. Journal of Experimental Psychology: Human Perception and Performance, 8, 24-36. 
Kumar, S., von Kriegstein, K., Friston, K., \& Griffiths, T. D. (2012). Features versus feelings: Dissociable representations of the acoustic features and valence of aversive sounds. Journal of Neuroscience, 32, 14184-92.

Ladinig, O., \& Schellenberg, E. G. (2012). Liking unfamiliar music: Effects of felt emotion and individual differences. Psychology of Aesthetics, Creativity, and the Arts, 6, 146-154.

Lartillot, O. (2014). MIRtoolbox 1.6.1. User's Manual. Retrieved from https://www.jyu.fi/hum/laitokset/musiikki/en/research/coe/materials/mirtoolbox/MIRtoolbox1.6.1guide. Accessed 8 June 2018.

Lartillot, O., \& Toiviainen, P. (2007). A Matlab Toolbox for Musical Feature Extraction From Audio. Proceedings of the 10th International Conference on Digital Audio Effects. Bordeaux, 2007. Retrieved from http://dafx.labri.fr/main/papers/p237.pdf. Accessed 8 June 2018.

Leaver, A.M., \& Halpern, A. R. (2004). Effects of training and melodic features on mode perception. Music Perception, 22, 117-143.

Lilja, E. (2005). Characteristics of Heavy Metal Chord Structures. Their Acoustic and Modal Construction, and Relation to Modal and Tonal Context. Licentiate Thesis. Univ. Helsinki.

Lilja, E. (2015). Dealing with the $3^{\text {rd. }}$ : Anatomy of distorted chords and subsequent compositional features of classic heavy metal. In T.-M. Karjalainen, \& K. Kärki (Eds.), Modern Heavy Metal Markets, Practices and Cultures. Helsinki (pp. 393-403). Helsinki: Aalto University.

MacCallum, J., \& Einbond, A. (2008). Real-Time analysis of Sensory Dissonance. In R. KronlandMartinet, S. Ystad, \& K. Jensen (Eds.), CMMR 2007 (pp. 203-211). Berlin: Springer.

Margulis, E. H., Mlsna, L. M., Uppunda, A. K., Parrish, T. B., \& Wong, P. C. M. (2009). Selective neurophysiologic responses to music in instrumentalists with different listening biographies. $\mathrm{Hu}$ man Brain Mapping, 30, 267-275.

McAdams, S., Depalle, P., \& Clarke, E. (2004). Analyzing Musical Sound. In E. Clarke, \& N. Cook (Eds.), Empirical Musicology. Aims. Methods. Prospects (pp. 157-196). Oxford: Oxford University Press.

McDermott, J. H., Lehr, A. J., \& Oxenham, A. J. (2010). Individual differences reveal the basis of consonance. Current Biology, 20, 1035-1041.

McDermot, J. H., Schultz, A. F., Undurraga, E. A., \& Godoy, R. A. (2016). Indifference to dissonance in native Amazonians reveals cultural variation in music perception. Nature, 535, 547-550.

McDonald, C. (2000). Exploring modal subversions in alternative music. Popular Music, 19(3), 355363.

McLachlan, N., Marco, D., Light, M., \& Wilson, S. (2013). Consonance and pitch. Journal of Experimental Psychology: General, 142, 1142-1158.

Mellers, W. (1973). Twilight of the Gods. The Beatles in Retrospect. New York: Viking.

Meltzer, R. (1970). The Aesthetics of Rock. New York: Da Capo Press.

Mende, W., Herzel, H., \& Wermeke, K. (1990). Bifurcations and chaos in newborn infant cries. Physics Letters A, 145, 418-424.

MIZ (2018). Bevorzugte Musikrichtungen nach Altersgruppen. Retrieved from http://www.miz.org/downloads/statistik/31/31_Bevorzugte_Musikrichtungen_Altersgruppen.pdf. Accessed 10 June 2018.

Moore, A. F. (2001). Rock the primary text: Developing a musicology of rock. Aldershot: Ashgate.

Moore, B. C., Glasberg, B. R., \& Baer, T. (1997). A model for the prediction of thresholds, loudness, and partial loudness. Journal of the Audio Engineering Society, 45(4), 224-240. 
Müllensiefen, D., Gingras, D., Musil, J., \& Stewart, L. (2014). The musicality of nonmusicians: An index for assessing musical sophistication in the general population. PLOS ONE, 9, e89642.

Müller, M. (2015). Fundamentals of Music processing. Audio, Analysis, Algorithms, Applications. Heidelberg: Springer.

Mynett, M. (2017). Metal Music Manual. Producing, Engineering, Mixing, and Mastering Contemporary Heavy Music. Oxon: Routledge.

Parncutt, R. (2006). Commentary on Cook \& Fujisawa's "The Psychophysics of Harmony Perception: Harmony is a Three-Tone Phenomenon". Empirical Musicological Review, 1 (4), 204-209.

Pierce, J. R. (1996). The Science of Musical Sound. New York: W. H. Freeman and Company.

Plomp, R., \& Levelt, W. J. M. (1965). Tonal consonance and critical bandwidth. Journal of the Acoustical Society of America, 38, 548-560.

Reyes, I. (2013). Blacker than Death: Recollecting the "Black Turn" in Metal Aesthetics. Journal of Popular Music Studies, 25(2), 240-257.

Roberts, L. A. (1986). Consonant judgments of musical chords by musicians and untrained listeners. Acustica, 62, 163-171.

Roederer, J. H. (1973). The Physics and Psychophysics of Music: An Introduction. 4th ed. New York: Springer.

Rossing, T. D., Moore, R., \& Wheeler, P. (2002). The science of sound. 3rd ed. San Francisco: Pearson Education.

Schubert, E., \& Wolfe, J. (2006). Does timbral brightness scale with frequency and spectral centroid? Acta acustica united with acustica, 92(5), 820-825.

Sethares, W. A. (1998). Tuning, Timbre, Spectrum, Scale. London: Springer.

Spreckelmeyer, K. N., Altenmüller, E., Colonius, H., \& Münte, T. (2013). Preattentive processing of emotional musical tones: A multidimensional scaling and ERP study. Frontiers in Psychology, 4(656).

Stephenson, K. 2002. What to Listen for in Rock: A Stylistic Analysis. New Haven: Yale University Press.

Tenney, J. (1988). A History of 'Consonance' and 'Dissonance'. New York: Excelsior Music Publishing Company.

Terhardt, E. (1984). The Concept of Musical Consonance: A Link Between Music and Psychoacoustics. Music Perception, 1(3), 276-295.

Tervaniemi, M., Janhunen, L., Kruck, S., Putkinen, V., \& Huotilainen, M. (2015). Auditory profiles of classical, jazz, and rock musicians: Genre-specific sensitivity to musical sound features. Frontiers in Psychology, 6, 1900.

Vassilakis, P. N. (2001). Perceptual and Physical Properties of Amplitude Fluctuation and their Musical Significance. Ph.D. thesis. Los Angeles: University of California.

Virtala, P., \& Tervaniemi, M. (2017): Neurocognition of Major-Minor and Consonance-Dissonance. Music Perception, 34(4), 387-404.

Virtala, P., Huotilainen, M., Lilja, Esa, Ojala, J., \& Tervaniemi, M. (2018). Distortion and Western Music Chord Processing: An ERP Study of Musicians and Nonmusicians. Music Perception, 35(3), 315-331.

Vuoskoski, J. K., Thompson, W. F., McIlwain, D., \& Eerola, T. (2012). Who enjoys listening to sad music and why? Music Perception, 29, 311-317. 
Vuust, P., Brattico, E., Seppänen, M., Näätänen, R., \& Tervaniemi, M. (2012). The sound of music: Differentiating musicians using a fast, musical multi-feature mismatch negativity paradigm. $\mathrm{Neu}$ ropsychologia, 50, 1432-1443.

Wallmark, Z., Iacoboni, M., Deblieck, C., \& Kendall, R. A. (2018). Embodied listening and timbre: Perceptual, acoustical, and neural correlates. Music Perception, 35(3), 332-363.

Walser, R. (1993). Running with the devil. Power, gender, and madness in heavy metal music. Hanover: Wesleyan University Press.

Wessel, D. L. (1979). Timbre space as a musical control structure. Computer Music Journal, 3(2), 4552.

Wicke, P. (1990). Rock Music. Culture, aesthetics and sociology. Cambridge: Cambridge University Press.

Winkler, P. (1978). Towards a theory of popular harmony. Theory Only, 4, 3-26.

Zollner, M (2014). Physik der Elektrogitarre. Retrieved from http://gitec-forum.de/GitecWP/wp-content/uploads/2015/04/Physik-der-Elektrogitarre GITEC.pdf. Accessed 8 June 2018.

Zwicker, E., \& Fastl, H. (2007). Psychoacoustics. Facts and Models. Berlin: Springer. 